\title{
Thermal, FT-IR and dielectric studies of gel grown sodium oxalate single crystals
}

\author{
B B PAREKH ${ }^{\dagger}$, P M VYAS, SONAL R VASANT and M J JOSHI* \\ Physics Department, Saurashtra University, Rajkot 360 005, India \\ ${ }^{\dagger}$ Institute of Diploma Studies, Nirma University of Science and Technology, Ahmedabad 384 481, India
}

MS received 29 October 2007; revised 25 January 2008

\begin{abstract}
Oxalic acid metabolism is important in humans, animals and plants. The effect of oxalic acid sodium salt is widely studied in living body. The growth of sodium oxalate single crystals by gel growth is reported, which can be used to mimic the growth of crystals in vivo. The grown single crystals are colourless, transparent and prismatic. The crystals have been characterized by thermogravimetric analysis, FT-IR spectroscopy and dielectric response at various frequencies of applied field. The crystals become anhydrous at $129 \cdot 3^{\circ} \mathrm{C}$. Coats and Redfern relation is applied to evaluate the kinetic and thermodynamic parameters of dehydration. The dielectric study suggests very less variation of dielectric constant with frequency of applied field in the range of $1 \mathrm{kHz}-1 \mathrm{MHz}$. The nature of variation of imaginary part of complex permittivity, dielectric loss and a.c. resistivity with applied frequency has been reported.
\end{abstract}

Keywords. Gel growth; FT-IR; TGA; dielectric study; kinetic parameters; thermodynamic parameters.

\section{Introduction}

Oxalic acid and its salts play an important role in human body, animals, plants and micro-organisms. Oxalic acid is produced naturally in body when ascorbic acid and glycine are metabolized. Oxalic acid metabolisms in man (Hodgkinson and Zarembski 1968) and in oxalate accumulating plants (Yang and Loewus 1975; Caliskan 2000) have been explained. Oxalic acid metabolism responsible for increased mean plasma oxalic acid level leading to renal failure is studied (Balcke 1985). Increased plasma oxalic acid levels may be important for calcium oxalate deposits in uraemia (clinical syndrome due to renal failure). Sodium salt of oxalic acid, sodium oxalate, is highly toxic through all routes of exposure, having industrial applications such as in metal cleaning, leather tanning, electroplating bath, etc. The effect of sodium oxalate on living body has been widely reported. When rat received $10 \mathrm{mg}$ of sodium oxalate for 30 days, the presence of renal tubular dilation with oxalate deposits (or stenosis) was found (Ono and $\mathrm{Ki}$ kawa 1989). Oxalate crystals in rat kidneys by intraperitoneal (within peritoneal cavity) administration of sodium oxalate have been reported (Tawashi et al 1980). On the other hand, temporary paralysis of vagus mechanism in turtle heart by sodium citrate and sodium oxalate is reported (Shaefer 1936). Also, sodium oxalate toxicity has been

*Author for correspondence (mshilp24@rediffmail.com) discussed in terms of acute renal failure following its ingestion (Hamilton et al 1999).

Slow diffusion of reactants in the gel medium can be considered to mimic the growth of crystals in a body (Joseph et al 2005). Various roles of sodium oxalate crystals have prompted the present authors to study the growth of sodium oxalate crystals by gel method and characterize them by different techniques, viz. thermogravimetry, FT-IR and dielectric study.

\section{Experimental}

\subsection{Crystal growth}

The growth of sodium oxalate crystals has been carried out using single diffusion gel growth technique. Glass test tubes of $25 \mathrm{~mm}$ diameter and $150 \mathrm{~mm}$ length were used as crystal growth apparatus. Sodium metasilicate solution of 1.05 specific gravity was acidified by $3 \mathrm{~N}$ acetic acid in such a manner that $\mathrm{pH} 5$ could be set for the mixture. This was transferred into different test tubes and allowed to set into the gel form. Thereafter, $1.5 \mathrm{M}$ oxalic acid solution was poured onto the set gel. After a few days good quality, colourless, transparent, prismatic, single crystals of sodium oxalate were grown, which is shown in figure 1 .

When sodium metasilicate goes into solution, monosilicic acid is expected to be produced (Henisch 1996) according to the following reaction 


$$
\mathrm{Na}_{2} \mathrm{SiO}_{3}+3 \mathrm{H}_{2} \mathrm{O}=\mathrm{H}_{4} \mathrm{SiO}_{4}+2 \mathrm{NaOH} \text {. }
$$

This sodium hydroxide is expected to react with oxalic acid diffusing in a gel from the supernatant solution and forming sodium oxalate by the following reaction

$$
2 \mathrm{NaOH}+\mathrm{H}_{2} \mathrm{C}_{2} \mathrm{O}_{4}=\mathrm{Na}_{2} \mathrm{C}_{2} \mathrm{O}_{4}+4 \mathrm{H}_{2} \mathrm{O} \text {. }
$$

\subsection{Characterization technique}

The crystals were characterized by three different techniques. The FT-IR spectrum was recorded on BRUCKER IFS $66 \mathrm{~V}$ FT-IR spectrometer in the range from 400 $4000 \mathrm{~cm}^{-1}$ in $\mathrm{KBr}$ medium. The thermogravimetry analysis (TGA) was carried out using NETZSCH Geratebau $\mathrm{GmbH}$ from room temperature to $1000^{\circ} \mathrm{C}$ at a heating rate of $28^{\circ} \mathrm{C} / \mathrm{min}$. The dielectric measurements were carried out on powdered sample pellets at room temperature by using LCR meter model Agilent 4284-A, in the frequency range from $500 \mathrm{~Hz}-1 \mathrm{MHz}$.

\section{Results and discussion}

The presence of oxalates of metals is wide spread. Many times these minerals are formed as a result of expulsion of heavy metals from fungi, lichens and plants (FreyWyssling 1981; Arnott and Webb 1983; Chisholm et al 1987). Many oxalates exist in nature, for example, copper oxalate or moolooite (Chisholm et al 1987; Clarke and Williams 1986), ferrous oxalate or humboldtine (Manasse 1911; Rezek et al 1988), sodium oxalate or natroxalate and ammonium oxalate or oxammite (Winchell and Benoit 1951).

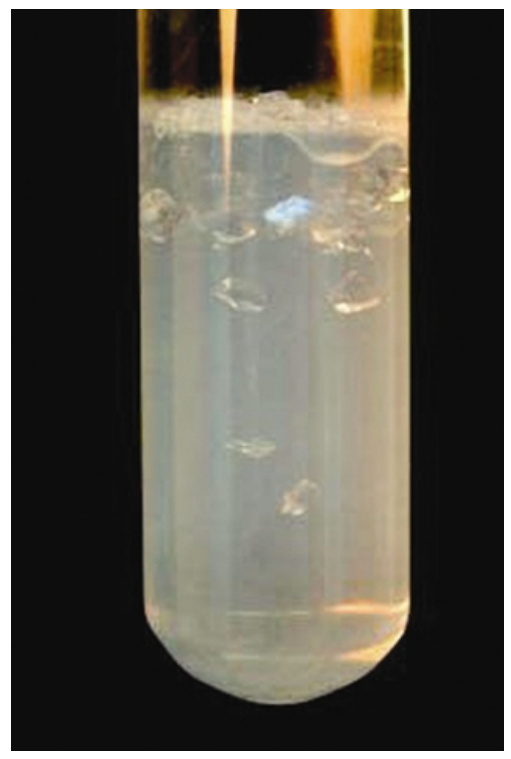

Figure 1. Growth of sodium oxalate monohydrate crystals in silica hydro-gel.
The crystal structure of sodium oxalate has been determined (Jeffrey and Parry 1954) with unit cell parameters obtained as $a=10.35 \pm 0.02 \AA, b=5.26 \pm 0.02 \AA, c=3.46 \pm$ $0.02 \AA$ and $\beta=92^{\circ} 54^{\prime} \pm 6^{\prime}$. Altogether, neutron diffraction study of sodium oxalate monohydrate crystal is reported at $123^{\circ} \mathrm{K}$ (Pederson and Kvick 1989). Mostly the growth of sodium oxalate is reported by aqueous solution method. The growth of sodium oxalate by aqueous solution slow evaporation technique and structural refinement is carried out (Reed and Ohnstead 1981). In another study, the growth from aqueous solution and in situ optical microscopic and atomic force microscopic observations are reported (Lowe et al 2002). The growth of single crystals has been monitored by optical microscopy on $\{001\}$ and $\{200\}$ faces. The $\{001\}$ and $\{200\}$ faces have been imaged at low supersaturation and room temperature display steps spreading with some apparent nucleation.

Thermal studies of certain oxalates of metals have been reported. Calcium oxalate monohydrate (Girija et al 1998) and humboldtine-ferrous oxalate (Frost and Weier 2004) have been investigated by conducting thermal analysis. In the present study, TGA of sodium oxalate was carried out up to $1000^{\circ} \mathrm{C}$ at a heating rate of $28^{\circ} \mathrm{C} / \mathrm{min}$. The thermogram is shown in figure 2. From the thermogram one can observe that the sample lost its water molecules at $129.3^{\circ} \mathrm{C}$ and became anhydrous. In the second stage, at $259.7^{\circ} \mathrm{C}$ the loss of $2 \mathrm{CO}$ is observed and in the following stage the $\frac{1}{2} \mathrm{O}_{2}$ is lost at $556 \cdot 9^{\circ} \mathrm{C}$. However, one water molecule was found to be associated with sodium oxalate crystals. Table 1 represents the decomposition process of sodium oxalate crystals.

Usually, the pyrolysis occurs through many stepped mechanisms. Various kinetic parameters such as the order of reaction, the frequency factor and the activation energy can be calculated from the thermogram. The authors have applied the Coats and Redfern relation (Coats and Redfern 1964) to evaluate the kinetic parameters for dehydration process from the thermogram. The Coats and Redfern relation is as follows, which has been discussed in detail elsewhere (Parekh and Joshi 2007)

$$
\begin{aligned}
& \log _{10}\left[\left\{1-(1-\alpha)^{1-n}\right\} /\left\{T^{2}(1-n)\right\}\right]= \\
& \quad\left\{\log _{10}[A R / \alpha E] \cdot[1-2 R T / E]\right\}-\{E / 2 \cdot 3 R T\},
\end{aligned}
$$

where $a$ is the fraction of the original substance decomposed at time $t, a=\left(W_{0}-W\right) /\left(W_{0}-W_{\mathrm{f}}\right), W_{0}$ the initial weight, $W$ the weight at time $t, W_{\mathrm{f}}$ the final weight, $n$ the order of reaction, $A$ the frequency factor, $E$ the activation energy, $R$ a gas constant and $a$ the heating rate in $\operatorname{deg} \mathrm{min}^{-1}$. Figure 3 is the best linear fitted plot for Coats and Redfern relation for $n=0$. The values of activation energy and frequency factors were calculated from the plot, which are given in table 2 . Thermodynamic parameters were also calculated using standard formulae reported elsewhere (Parekh and Joshi 2007). Table 2 shows the values of these parameters. The standard enthalpy, 


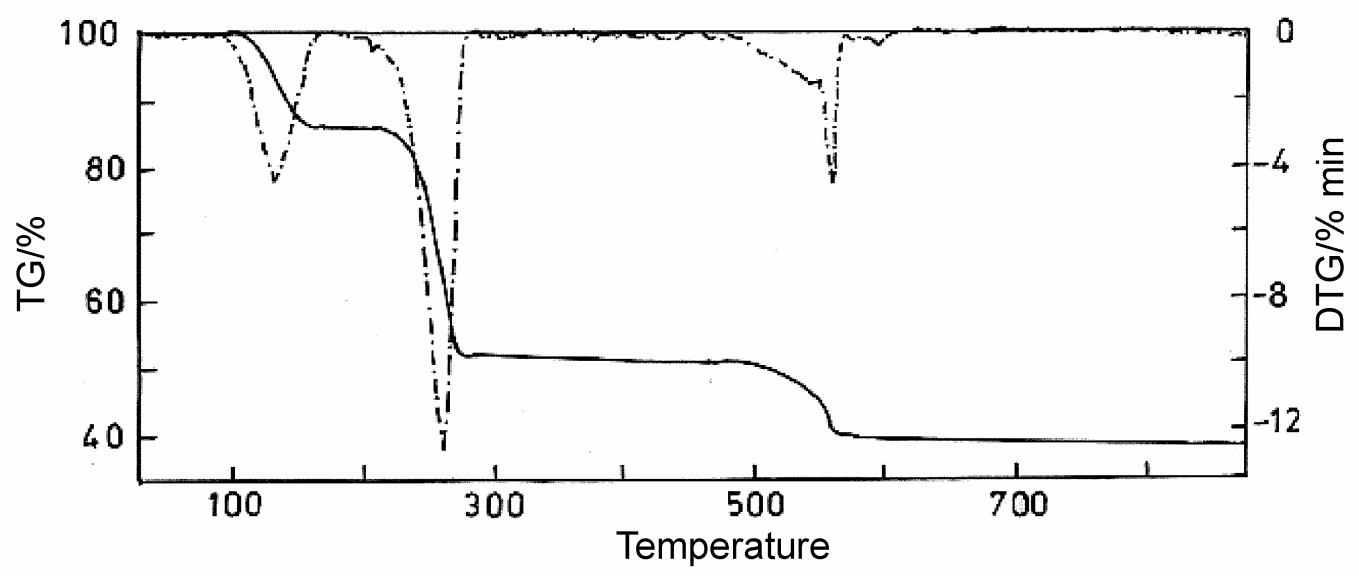

Figure 2. Thermogram of sodium oxalate monohydrate.

Table 1. Decomposition process of sodium oxalate monohydrate crystals and TG results.

\begin{tabular}{llcc}
\hline Temperature $\left({ }^{\circ} \mathrm{C}\right)$ & \multicolumn{1}{c}{ Substance } & $\begin{array}{c}\text { Theoretical weight } \\
(\%) \text { (calculated) }\end{array}$ & $\begin{array}{c}\text { Practical weight } \\
(\%) \text { (from graph) }\end{array}$ \\
\hline Room temperature & $\mathrm{Na}_{2} \mathrm{C}_{2} \mathrm{O}_{4} \cdot 1 \cdot 21 \mathrm{H}_{2} \mathrm{O}$ & 100 & 100 \\
$129 \cdot 3^{\circ} \mathrm{C}$ & $\mathrm{Na}_{2} \mathrm{C}_{2} \mathrm{O}_{4}$ & 85.99 & 85.99 \\
$259 \cdot 7^{\circ} \mathrm{C}$ & $\mathrm{Na}_{2} \mathrm{O}_{2}$ & $50 \cdot 19$ & 51.62 \\
$556.9^{\circ} \mathrm{C}$ & $\mathrm{Na}_{2} \mathrm{O}$ & 39.88 & 39.95 \\
\hline
\end{tabular}

Table 2. Kinetic and thermodynamic parameters of dehydration of sodium oxalate monohydrate.

\begin{tabular}{ll}
\hline Kinetic parameters & \multicolumn{1}{c}{ Thermodynamic parameters } \\
\hline Order of reaction $(n)=0$ & Standard entropy $\Delta^{\#} S^{\mathrm{o}}=82 \cdot 1696 \mathrm{~J} \mathrm{~mol}^{-1}$ \\
Activation energy $(E)=62.414 \mathrm{~kJ} \mathrm{~mol}^{-1}$ & Standard enthalpy $\Delta^{\#} H^{\mathrm{o}}=53 \cdot 708 \mathrm{~kJ} \mathrm{~mol}^{-1}$ \\
Frequency factor $(A)=2 \cdot 141 \times 10^{17}$ & Standard Gibbs free energy $\Delta^{\#} G^{\mathrm{o}}=10 \cdot 684 \mathrm{~kJ} \mathrm{~mol}^{-1}$ \\
& Standard change in internal energy $\Delta^{\#} U^{\mathrm{o}}=58 \cdot 0616 \mathrm{~mol}^{-1}$ \\
\hline
\end{tabular}

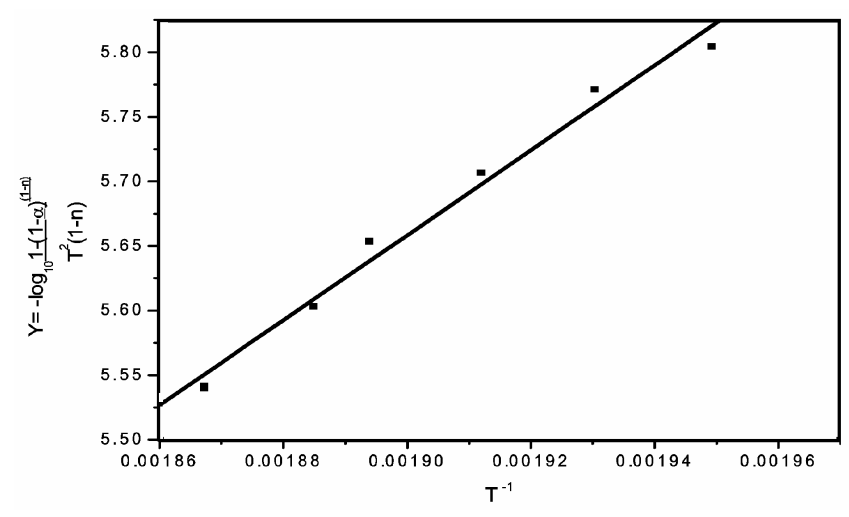

Figure 3. Plot of Coats and Redfern relation for sodium oxalate crystals.

$\Delta^{\#} H^{\circ}$, is positive, which indicates that the reaction is endothermic. The positive value of standard change in entropy, $\Delta^{\#} S^{o}$, indicates spontaneous type process. Also, the positive value of standard change in Gibbs free energy, $\Delta^{\#} G^{\circ}$, suggests spontaneous reaction.

The FT-IR spectroscopic studies of humboldtine $\left(\mathrm{FeC}_{2} \mathrm{O}_{4} 2 \mathrm{H}_{2} \mathrm{O}\right)$ (Frost and Weier 2004) and calcium oxalate monohydrate (Joshi 2001) have been reported. The FT-IR spectrum of sodium oxalate monohydrate is shown in figure 4 . The absorptions between $418 \mathrm{~cm}^{-1}$ and $600 \mathrm{~cm}^{-1}$ show the presence of oxygen metal bonds. Broad absorptions at $1741.6 \mathrm{~cm}^{-1}$ and $1613.3 \mathrm{~cm}^{-1}$ indicate the presence of more than one $\mathrm{C}=\mathrm{O}$ bond, while absorptions at $885.3 \mathrm{~cm}^{-1}, 1029.6 \mathrm{~cm}^{-1}$ and $1236.3 \mathrm{~cm}^{-1}$ are due to $\mathrm{C}-\mathrm{C}$ stretching vibrations. The presence of water of hydration is primarily confirmed by the presence of a sharp dip at $3407 \mathrm{~cm}^{-1}$, which is due to $\mathrm{O}-\mathrm{H}$ stretching.

Dielectric study of hydrated barium oxalate and cadmium oxalate crystals have been reported (Dharmaprakash and Rao 1989). The nature of variation of dielectric constant with frequency indicated that the higher space charge polarizability was present in the lower frequency region. The variation of dielectric constant with frequency is 


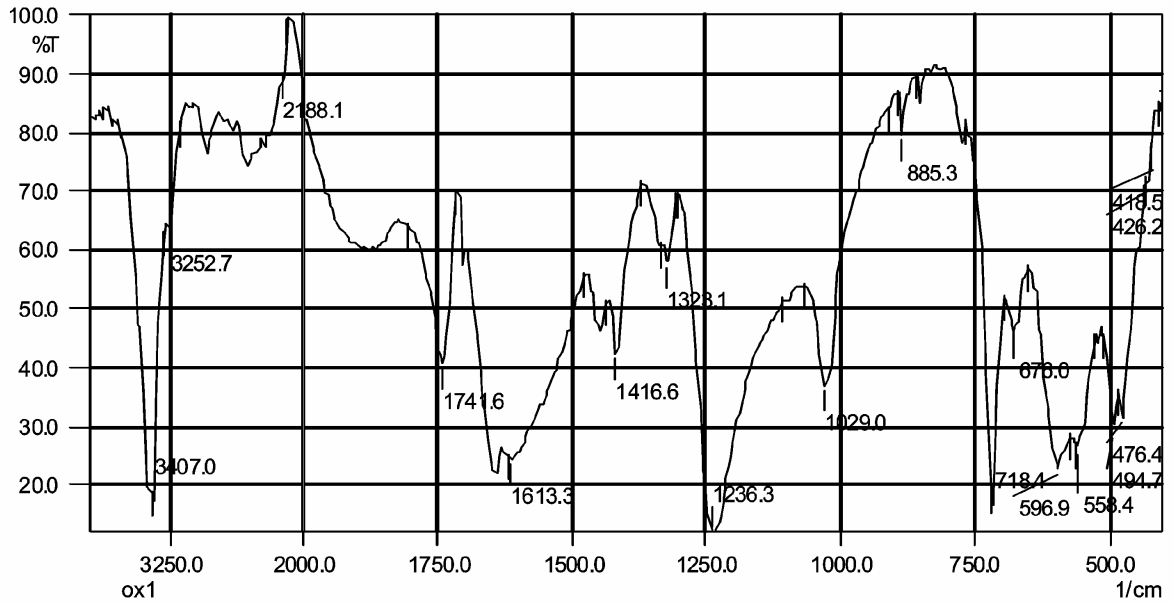

Figure 4. FT-IR spectrum of sodium oxalate crystals.

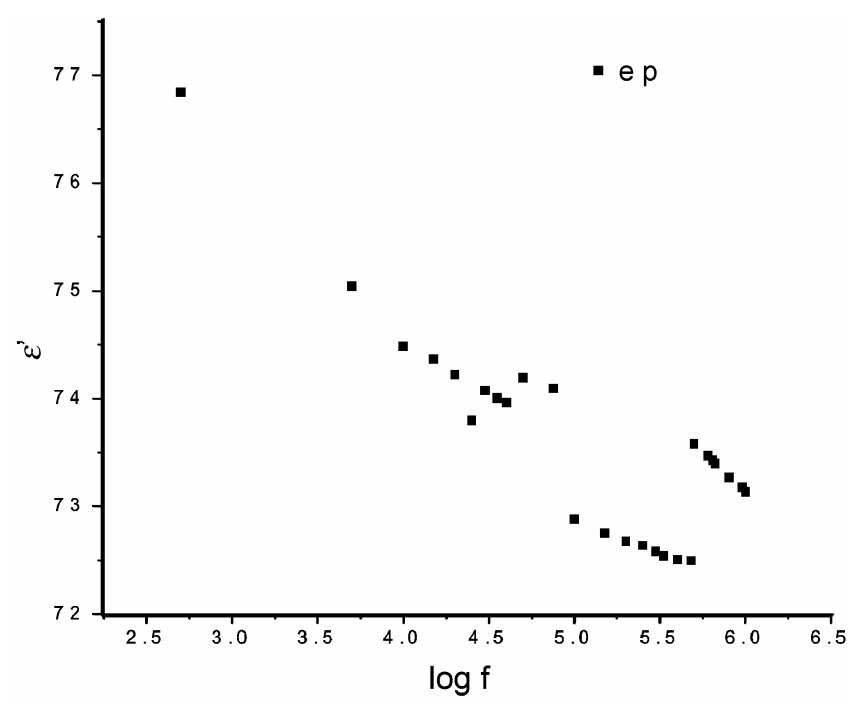

Figure 5. Plot of dielectric constant vs frequency of applied field.

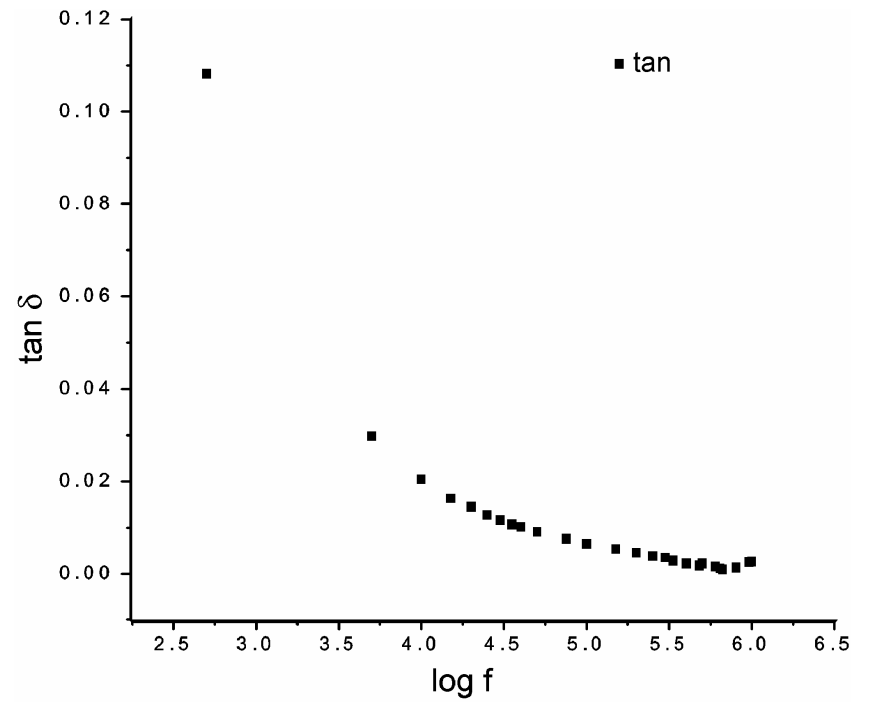

Figure 6. Plot of dielectric loss vs frequency of applied field.

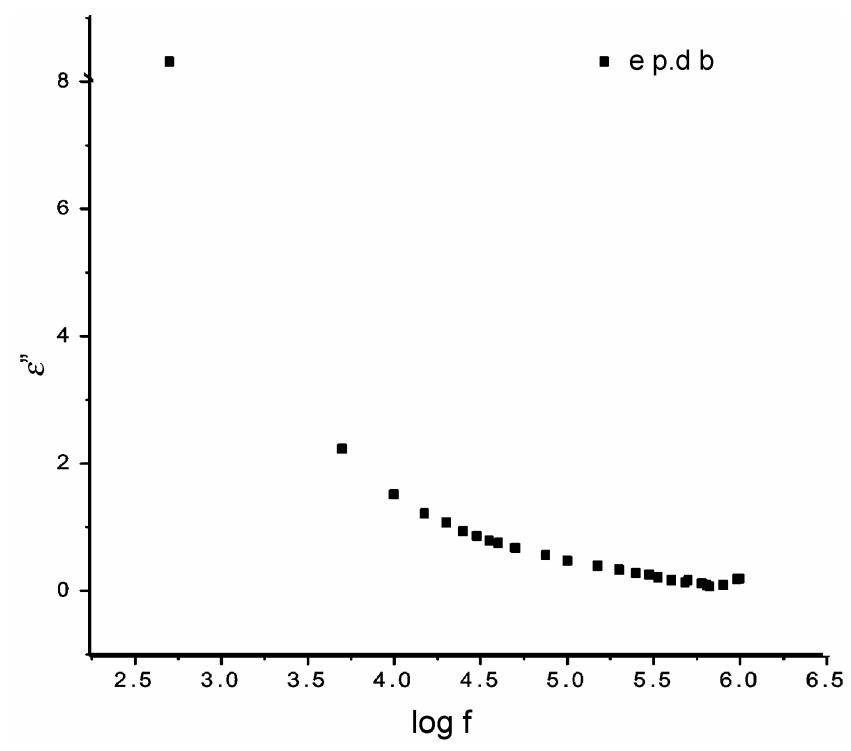

Figure 7. Plot of imaginary part of the complex permittivity vs frequency of applied field.

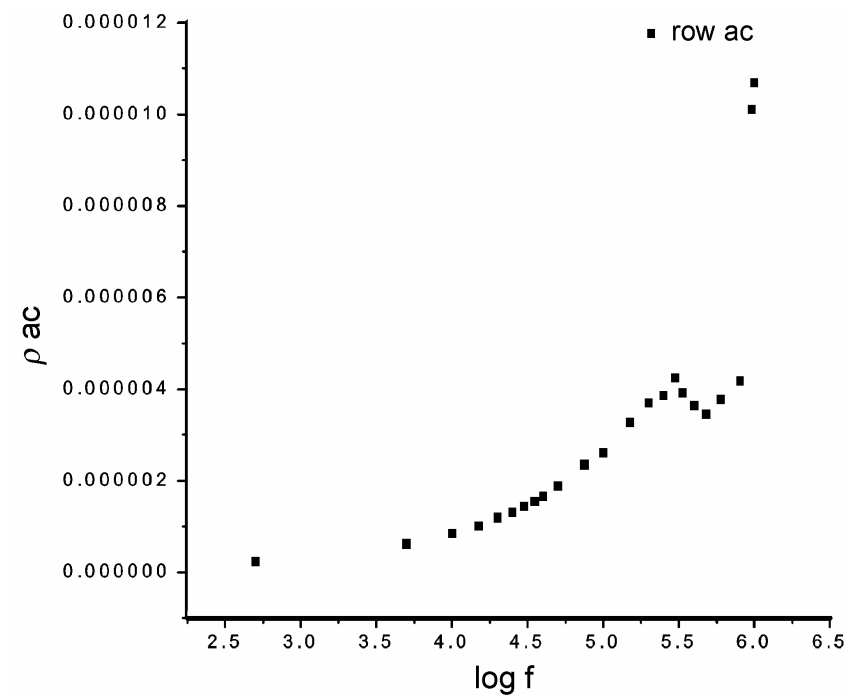

Figure 8. Plot of a.c. resistivity vs frequency of applied field. 
shown in figure 5. The plots suggest that as the frequency of applied field increases the dielectric constant decreases with some variations. However, the variation in the dielectric constant is very less, i.e. $\mathbf{7 6 . 8 4}$ maximum and 72.50 minimum, in the range of frequency of applied field.

Recently, the variation of dielectric constant, dielectric loss and a.c. conductivity with frequency of applied field was reported (Parekh and Joshi 2007) for calcium pyrophosphate tetrahydrate crystals. The variation of dielectric loss, $\tan \delta$, with applied field is shown in figure 6 , which suggests that the dielectric loss decreases as the frequency increases. The response of normal materials to external fields depends on the frequency of the applied field. In fact, polarization of material does not respond instantaneously to an applied field. For this reason the permittivity is often treated as a complex function of frequency of the applied field. The variation of imaginary part of the complex permittivity with frequency of applied field is shown in figure 7. This indicates that as the frequency increases the value of the imaginary part of the permittivity decreases. The nature of variation of a.c. resistivity with frequency of applied field is shown in figure 8 . This indicates that as the frequency of the applied field increases the a.c. resistivity increases rapidly.

\section{Conclusions}

Growth of sodium oxalate crystals was carried out by single diffusion gel growth technique. Good quality, transparent, prismatic, single crystals were harvested. The crystal is thermally unstable and decomposes through three stages into sodium oxide form at $556.9^{\circ} \mathrm{C}$. One water molecule was found to be associated with the crystal. The kinetic parameters of dehydration were calculated by applying Coats and Redfern relation to thermogram. Thermodynamic parameters were also evaluated which suggest the spontaneous type nature of reaction. The FT-IR spectrum indicated the presence of $\mathrm{C}=\mathrm{O}$ bond, $\mathrm{C}-\mathrm{C}$ bond and $\mathrm{O}-\mathrm{H}$ bond. As the frequency of the applied field increases the dielectric constant decreases, however, the response was found to be very poor. The dielectric loss $(\tan \delta)$ and the imaginary part of the complex permittivity decreased as the frequency of the field increased. However, the a.c. resistivity increased rapidly as the frequency of the applied field increased.

\section{Acknowledgements}

The authors are thankful to UGC, New Delhi, for the SAP and Profs K N Iyer and H H Joshi for keen interest. One of the authors (BBP) is thankful to DBT, New Delhi, for JRF and SRF and the authority of Nirma University, Ahmedabad, for encouragement.

\section{References}

Arnott H J and Webb M A 1983 Scann. Electron Microsc. 41 Balcke P 1985 Wien Klin Wochenschr. Suppl. 1601

Caliskan M 2000 Turk. J. Zool. 24103

Chisholm J E, Jones G C and Purvis O W 1987 Miner. Mag. 51 715

Clarke R M and Williams I R 1986 Miner. Mag. 50295

Coats A W and Redfern J P 1964 Nature 20168

Dharmaprakash S M and Mohan Rao P 1989 J. Mater. Sci. Lett. 81167

Frey-Wyssling A 1981 Am. J. Bot. 68130

Frost R L and Weier M L 2004 Thermal Analysis and Calorimetry 75277

Girija E K, Charistic Latha S, Kalkura S N, Subramanian C and Ramasamy P 1998 Mater. Chem. \& Phys. 52253

Hamilton S E, Pielage P J and Fassett R G 1999 Emergency Medicine Australasia 1135

Henisch H K 1996 Crystal growth in gels (New York: Dover)

Hodgkinson A and Zarembski P M 1968 Calcified Tissue Int. 2 115

Jeffrey G A and Parry G S 1954 J. Am. Chem. Soc. 765283

Joseph K C, Parekh B B and Joshi M J 2005 Curr. Sci. 88 1232

Joshi V S 2001 Crystal growth and characterization of some urinary crystals, Ph.D. Thesis, Saurashtra University, Rajkot

Lowe J, Ogden M, Mckinnon A and Parkinson G 2002 J. Cryst. Growth 237-239 408

Manasse E 1911 Rend. Acad. Lincei 19138

Ono K and Kikawa K 1989 ASAIO Trans. 35629

Pederson B F and Kvick A 1989 Acta Crystallogr. C45 1724

Parekh B B and Joshi M J 2007 Cryst. Res. \& Technol. 42127

Reed D A and Ohnstead M M 1981 Acta Crystallogr. B37 938

Rezek K, Sevcu J, Civiš S and Novotný J 1988 Pro Mineralogii a Geologii Casopis 33419

Shaefer G D 1936 J. Pharmacol. \& Exptl. Therapeut. 58264

Tawashi R, Cousineau M and Sharkawi M 1980 Invest. Urol. 1890

Winchell H and Benoit R J 1951 Am. Mineral. 36590

Yang J C and Loewus F A 1975 Plant Physiol. 56283 